\title{
Apnea as a Complication of Intravenous Immunoglobulin Therapy in a Neonate
}

\author{
Ashok Kumar • Rishi Kapoor • Sriparna Basu
}

Received: 27 February 2014 / Accepted: 5 June 2014 / Published online: 19 June 2014

(C) Dr. K C Chaudhuri Foundation 2014

To the Editor: Intravenous immunoglobulin (IVIG) is used in neonates as an adjunctive therapy in $\mathrm{Rh}$ hemolytic disease (RHD). We report a neonate developing apnea after its use.

A second gravida $\mathrm{O} \mathrm{Rh}$-negative mother delivered a premature $(35+5 \mathrm{wk}, 2075 \mathrm{~g})$ baby boy. Her first child did not have any neonatal jaundice. She never received anti-D immunoglobulin and anti-D titer was not done. At birth the neonate (O Rh-positive) was clinically normal. Icterus was evident at $11 \mathrm{~h}$. Investigations revealed hemoglobin $-12.8 \mathrm{~g} / \mathrm{dl}$, total serum bilirubin (TSB) - $6.4 \mathrm{mg} / \mathrm{dl}$, reticulocyte count-18 \%, positive indirect Coomb's test and evidences of hemolysis in peripheral smear. Intensive phototherapy was started but TSB increased to $15.4 \mathrm{mg} / \mathrm{dl}$ at $42 \mathrm{~h}$, and first double-volume exchange transfusion (DVET) was done. Second DVET was done at $96 \mathrm{~h}$ at TSB of $18.4 \mathrm{mg} / \mathrm{dl}$. To avoid further DVET, IVIG infusion $(1 \mathrm{~g} / \mathrm{kg})$ was planned. Normal human immunoglobulin, well within the expiry date, was used.

Infusion was started at $1 \mathrm{ml} / \mathrm{kg} / \mathrm{h}$ in a separate line. After 10 min of starting infusion, the neonate went into sudden apnea, bradycardia and desaturation which responded to positive pressure ventilation (PPV). Infusion was stopped immediately. There was no feature of anaphylactic reaction, shock, hypo/hyperthermia, hypoglycemia, hematuria and dyselectrolytemia. It was difficult to decide whether the apnea was induced by IVIG or it was mere coincidence. IVIG infusion was restarted after $1 \mathrm{~h}$ at a reduced rate $(0.5 \mathrm{ml} / \mathrm{kg} / \mathrm{h})$. Within $2 \mathrm{~min}$ the neonate went into apnea again and needed PPV. The drug was discarded. The baby remained stable

\footnotetext{
A. Kumar • R. Kapoor $\cdot$ S. Basu $(\bowtie)$

The Neonatal Unit, Department of Pediatrics, Institute of Medical Sciences, Banaras Hindu University, Varanasi 221005, India e-mail: drsriparnabasu@rediffmail.com
}

thereafter. Complete blood count, sepsis screen including blood culture, coagulation profile and renal function test remained normal.

Adverse events of IVIG varies widely from 1 to $81 \%$ [1]. Their etiology remains uncertain, but IgG aggregates and complement activation appear to be involved [2]. Immediate reactions are usually mild and transient including headache, facial flushing, malaise, fever, chills, dyspnea, vomiting, diarrhea, hypo/hypertension and tachycardia [3]. Acute kidney injury, necrotizing enterocolitis, hypoglycemia, hemolytic anemia, leukopenia, neutropenia, disseminated intravascular coagulation and severe deep vein thrombosis have been reported in neonates [3, 4]. Apnea has never been reported before and we emphasize the need for cautious use of IVIG in neonates.

Conflict of Interest None.

Source of Funding None.

\section{References}

1. Orbach H, Katz U, Sherer Y, Shoenfeld Y. Intravenous immunoglobulin: adverse effects and safe administration. Clin Rev Allergy Immunol. 2005;29:173-84.

2. Gottstein R, Cooke RW. Systematic review of intravenous immunoglobulin in haemolytic disease of the newborn. Arch Dis Child Fetal Neonatal Ed. 2003;88:F6-10.

3. Wittstock M, Benecke R, Zettl UK. Therapy with intravenous immunoglobulins: complications and side-effects. Eur Neurol. 2003;50: $172-5$.

4. Fanaroff AA, Korones SB, Wright LL, Wright EC, Poland RL, Bauer $\mathrm{CB}$, et al. A controlled trial of intravenous immune globulin to reduce nosocomial infections in very-low-birth-weight infants. National Institute of Child Health and Human Development Neonatal Research Network. N Engl J Med. 1994;330:1107-13. 